\title{
Cintilografia Miocárdica para Pesquisa de Inflamação Miocárdica
}

A presença de inflamação miocárdica pode ser detectada por radiotraçadores que são captados no miocárdio. Os mais utilizados são o pirofosfato- ${ }^{99 \mathrm{~m} T c, 0}$ citrato de gálio-67 e anticorpos antimiosina marcados com tecnécio-99m ou com índio-111.

Aspectos técnicos - A cintilografia com pirofosfato${ }^{99 m} \mathrm{mc}$ é realizada 1 hora após a dose de 10 a $15 \mathrm{mCi}$ do material, com o paciente posicionado em decúbito dorsal e a aquisição nas projeções anterior do tórax, oblíqua anterior esquerda (OAE) a $45^{\circ}$ e $60^{\circ}$ e perfil esquerdo para imagens planas. A câmara de cintilação deve ser calibrada para o fotopico de $140 \mathrm{keV}$ e janela de $15 \%$ com aquisição de 1 milhão de contagens. A cintilografia com gálio-67 é realizada 48 a 72 horas após a dose venosa de 3 a $5 \mathrm{mCi}$, em decúbito dorsal nas projeções anterior do tórax, $45^{\circ}$ e perfil esquerdo. Pode-se ainda adquirir imagens pela técnica tomográfica. No estudo normal, não há captação cardíaca e, nos anormais, a intensidade da captação miocárdica é comparada à captação óssea adjacente (menor, igual ou maior).

Diagnóstico - O pirofosfato-99mTc (PYP-99mTc) é um marcador de necrose e, portanto, depende da exposição da miosina para causar captação cardíaca. Entretanto, vários são os trabalhos que mostram a captação de PYP-99mTc em músculo inflamado, como ocorre na miocardite. O citrato de gálio-67, quando injetado na circulação, liga-se aos sítios livres de ferro da transferrina e é carreado para as áreas inflamadas, transudando para o interstício através do aumento da permeabilidade capilar. Existem outros mecanismos de captação, porém de menor importância. 0 valor preditivo negativo é de 83 a $98 \%$ e sensibilidade da ordem de $83 \%$. Anticorpos monoclonais antimiosina marcados com tecnécio-99m ou índio-111 fixam-se à miosina exposta devido à agressão tissular. Apesar da esperada especificidade, ocorre também em processos inflamatórios sem necrose. 0 valor preditivo negativo é de $92 \%$, mas a especificidade é da ordem de $53 \%$.

\section{REFERÊNCIAS}

1. Kühl U, Lauer B, Souvatzoglu M, Vosberg H, Schultheiss HP. Antimyosin scintigraphy and immunohistologic analysis of endomyocardial biopsy in patients with clinical suspected myocarditis - evidence of myocardial cell damage and inflammation in the absence of histologic signs of myocarditis. J Am Coll Cardiol, 1998; 32: 1371-76

2. Kawai C. From myocarditis to cardiomyopathy: mechanisms of inflammation and cell death. Circulation 1999; 99: 1091-1100.

3. Martin AB, Webber S, Fricker FJ et al. Acute myocarditis. Rapid diagnosis by PCR in children. Circulation 1994; 90:330-9.

4. Hufnagel G, Pankuweit S, Richter A, Schonian U, Maisch B. The European study of epidemiology and treatment of cardiac inflammatory diseases (ESETCID). First epidemiological results. Herz 2000; 25: 279-85.
5. Baccara F, Blanchard-Lemoine B, Sarda L et al. Diagnostic strategy in acute myocarditis. Arch Mal Coeur Vaiss 1998; 91: 1151-8.

6. Schutz A, Breuer M, Kemkes BM. Antimyosin antibodies in cardiac rejection. Ann Thorac Surg 1997; 63: 578-81.

7. Jolles PR, Tatum JL. SLE myocarditis. Detection by Ga-67 citrate scintigraphy. Clin Nucl Med 1996; 21 : 284-6.

8. Alexander C, Oberhausen E. Myocardial scintigraphy. Semin Nucl Med $1995 ; 25: 195-201$.

9. Soares J Jr, Snitcowski R, Assis RVCX et al. Gallium-67 scintigraphy in the diagnosis and follow-up of rheumatic carditis. World J Nucl Med 2002; 138-139. 